\title{
Acute Response to Aerobic Exercise on Autonomic Cardiac Control of Patients in Phase III of a Cardiovascular Rehabilitation Program Following Coronary Artery Bypass Grafting
}

Bruno Bavaresco Gambassi', PhD; Fabiano de Jesus Furtado Almeida1,2,3, MsC; Ana Eugênia Araújo Furtado Almeida ${ }^{1}$, PhD; Daniela Alves Flexa Ribeiro ${ }^{1}, \mathrm{MsC}$; Rômulo Sérgio Araújo Gomes ${ }^{4}$, MD; Luiz Filipe Costa Chaves ${ }^{1}$, Lic; Thiago Matheus da Silva Sousa ${ }^{1}$, Lic; Vinicius José da Silva Nina ${ }^{2,4}$, MD, PhD

\section{Abstract}

Objective: The aim of the present study was to investigate the acute response to aerobic exercise on autonomic cardiac control of patients undergoing coronary artery bypass grafting (CABG).

Methods: The study sample consisted of eight patients (age: $58.6 \pm 7.7$ years; body mass index: $26.7 \pm 3.5 \mathrm{~kg} . \mathrm{m} 2$ ) who underwent a successful CABG (no complications during surgery and/or in the following weeks). To assess heart rate variability (HRV), participants remained in a supine position with a 30-degree head elevation for 20 minutes. Electrocardiographic signal (protocol with three derivations) was collected from $600 \mathrm{~Hz}$ sample rate to obtain beatto-beat intervals (R-R interval). This assessment was performed before, after one hour and after $\mathbf{2 4}$ hours of the exercise session. All patients underwent a $\mathbf{3 5}$ minutes aerobic exercise session (AES) (low-moderate intensity) on the cycle ergometer.

Results: Significant differences were found in the time domain, with positive changes in root mean square of successive RR interval differences (rMSSD) (ms) (parasympathetic component) (one $[P=0.017]$ and 24 hours $[P=0.007]$ post-session). In the frequency domain, we found a significant difference in high frequency (HF) (ms2) (parasympathetic component) (one hour $[P=0.048]$ post-session). The low frequency (LF)/HF ratio (sympathetic and parasympathetic components with a predominance of the sympathetic component) reached statistical significance only 24 hours $(P=0.018)$ post-session. Additionally, the largest effect size was observed only for the LF/HF ratio at one $(d=-0.8)$ and 24 hours $(d=-1.3)$ after one AES.

Conclusion: The practice of (acute) aerobic exercise improved autonomic cardiac control in patients undergoing CABG.

Keywords: Cardiovascular Surgical Procedures. Autonomic Nervous System. Heart Rate. Exercise.

\begin{tabular}{|c|c|c|c|}
\hline \multicolumn{4}{|c|}{ Abbreviations, acronyms \& symbols } \\
\hline AES & $=$ Aerobic exercise session & HUUFMA & = Hospital Universitário da Universidade Federal do \\
\hline ANOVA & $=$ Analysis of variance & & Maranhão ou University Hospital of Federal University \\
\hline CABG & $=$ Coronary artery bypass grafting & & of Maranhão \\
\hline ES & $=$ Effect size & LF & $=$ Low frequency \\
\hline $\mathbf{F}$ & $=$ Female & M & $=$ Male \\
\hline FAPEMA & $\begin{aligned}= & \text { Fundação de Amparo à Pesquisa e ao Desenvolvimento } \\
& \text { Científico e Tecnológico do Maranhão }\end{aligned}$ & pNN50 & $\begin{aligned}= & \text { Percentage of successive RR intervals that differ by } \\
& \text { more than } 50 \mathrm{~ms}\end{aligned}$ \\
\hline FFT & $=$ Fast Fourier Transform & rMSSD & $=$ Root mean square of successive RR interval \\
\hline HF & $=$ High frequency & & differences \\
\hline HR & $=$ Heart rate & SD & $=$ Standard deviation \\
\hline HRV & $=$ Heart rate variability & SDNN & $=$ Standard deviation of NN intervals \\
\hline
\end{tabular}

'Department of Physical Education, Universidade Ceuma, São Luís, MA, Brazil.

2Programa de Pós-Graduação em Ciências da Saúde, Universidade Federal do Maranhão (UFMA), São Luís, MA, Brazil.

${ }^{3}$ Department of Physical Education, Universidade Estadual do Maranhão (UEMA), São Luís, MA, Brazil.

${ }^{4}$ Hospital Universitário da Universidade Federal do Maranhão (HUUFMA), São Luís, MA, Brazil.

This study was carried out at the Universidade Federal do Maranhão (UFMA), São Luís, MA, Brazil.
Correspondence Address:

Vinicius José da Silva Nina

iD https://orcid.org/0000-0003-3017-7459

Hospital Universitário da Universidade Federal do Maranhão (HUUFMA)

R. Barão de Itapari, 227 - Centro, São Luís, MA, Brazil.

Zip Code: 65020-070

E-mail: rvnina@terra.com.br 


\section{INTRODUCTION}

Heart rate variability (HRV) reflects the variation in time between each heartbeat, indicating the ability of autonomic cardiac control to respond to multiple physiological stimuli, such as metabolic and mechanical alterations ${ }^{[1,2]}$. This process results from the interaction between stimuli traveling via afferent pathways and responses to the efferent pathways ${ }^{[1,2]}$.

Any negative changes in the interaction between the central and peripheral nervous systems (afferent and/or efferent pathways) decrease HRV, thus impairing autonomic cardiac control and increasing the risk of cardiac death ${ }^{[3-6]}$. In this sense, Kleiger et al. ${ }^{[6]}$ have demonstrated a strong relationship between mortality risk and impaired autonomic cardiac control in patients after acute myocardial infarction. Additionally, Quintana et al. ${ }^{[7]}$ have found out that patients who had nonfatal infarction and cardiac events (death or revascularization) presented lower HRV when compared to patients without these conditions.

On the other hand, the practice of physical exercise may be used as an effective non-pharmacological strategy to increase $\mathrm{HRV}^{[8,9]}$ and consequently reduce the aforementioned risks ${ }^{[3-6]}$. Although Bilińska et al. ${ }^{[10]}$, Takeyama et al. ${ }^{[1]}$, and Wolszakiewicz et al. ${ }^{[12]}$ have demonstrated positive effects of physical exercise on autonomic cardiac control in patients after coronary artery bypass grafting (CABG), few studies to date have focused on this topic ${ }^{[13]}$.

Additionally, after assessing a review study carried out by Almeida et al. ${ }^{[13]}$, we noticed the paucity of research involving $H R V$, exercise, and patients undergoing CABG. Since many health professionals work with this population, they must resort to the few published relevant studies to prescribe the safest and most effective training protocol. As such, further studies on this topic are needed. Thus, the aim of the present study was to investigate the acute response to aerobic exercise on the autonomic cardiac control of patients undergoing CABG.

\section{METHODS}

\section{Patients}

This is an experimental study, with pre and posttreatment tests designed for one group. Using a convenience sampling, we recruited patients from the cardiac rehabilitation program at the Department of Cardiac Surgery of the University Hospital of Federal University of Maranhão (HUUFMA), President Dutra Unit, São Luís, MA, Brazil. All patients signed an informed consent form after being properly instructed about the study proposal, the procedures they would have to undergo, and their potential risks and benefits.

The inclusion criteria were: patients who underwent a successful CABG (no complications during surgery and/or in the following weeks), with normal ejection fraction (>50\%), Class I (according to New York Heart Association), who participated in phases I and II of cardiac rehabilitation, not using any beta blockers (e.g., atenolol), and having no impairment in the musculoskeletal system.

Patients were excluded if they had a clinical diagnosis of diabetes mellitus (uncontrolled), hypertension (uncontrolled), physical discomfort at any stage of the study and/or any reaction to the tests (nausea, dizziness, discomfort, feeling faint, tachycardia, excessive sweating), and if they failed to attend the scheduled sessions.
The study sample consisted of eight patients (five males and three females) with mean age of 58.6 \pm 7.7 years and mean body mass index of $26.7 \pm 3.5 \mathrm{~kg} \cdot \mathrm{m}^{2}$ (Table 1).

\section{Procedures}

From the first to the fourth visit to the laboratory, anthropometric measurements were carried out, and participants were familiarized with the assessment procedures and the exercise protocol on the cycle ergometer. In the following week, evaluations were undertaken, and the exercise protocol was started.

\section{Anthropometric Measurements}

Total body mass in kilograms $(\mathrm{kg})$ and height in centimeters (cm) were measured using an anthropometric scale (PL-200, Filizola S.A. Pesagem e Automação, São Paulo, SP, Brazil), with an accuracy of $50 \mathrm{~g}$ and $0.1 \mathrm{~cm}$, properly calibrated (NBR ISO/IEC 17025:2005). Body mass index was determined by body mass $(\mathrm{kg})$ divided by the square of height $\left(\mathrm{m}^{2}\right)$.

\section{Experimental Protocol}

All patients underwent an aerobic exercise session (AES) on the cycle ergometer. The session consisted of the following:

- Five minutes of low-intensity warm-up (ranging from 7 to 9 CR-10 [Borg scale]);

- 25 minutes of moderate-intensity exercise (resting heart rate +30 beats and ranging from 11 to 13 CR-10 [Borg scale]);

- Five minutes of low-intensity exercise (ranging from 7 to 9 CR-10 [Borg scale] $\left.)^{[14,15}\right]$.

Table 1. Study patients' clinical profile $(\mathrm{N}=8)$.

\begin{tabular}{l|c}
\hline \multicolumn{1}{l|}{ Clinical data } & Patients \\
\hline Baseline characteristics & $58.6 \pm 7.7$ \\
\hline Age (years) & $05(62.5) / 03(37.5)$ \\
\hline Gender, M/F, N (\%) & $26.7 \pm 3.5$ \\
\hline Body mass index (kg/m $\left.{ }^{2}\right)$ & $05(62.5)$ \\
\hline Associated comorbidities & $03(37.5)$ \\
\hline Diabetes, N (\%) & \\
\hline Hypertension, N (\%) & $06(75)$ \\
\hline Medication & $03(37.5)$ \\
\hline Angiotensin-converting enzyme & $04(50)$ \\
\hline Antiplatelet agents, N (\%)
\end{tabular}

Data are expressed as mean \pm standard deviation or absolute values and percentages.

$\mathrm{F}=$ female; $\mathrm{M}=$ male 


\section{Assessment of Heart Rate Variability (Autonomic Cardiac Control)}

To assess HRV, participants remained in a supine position with 30-degree head elevation for 20 minutes. Electrocardiographic signal (protocol with three derivations) was collected from 600 $\mathrm{Hz}$ sample rate to obtain beat-to-beat intervals ( $\mathrm{R}$ - $\mathrm{R}$ interval). This assessment was performed before, after one hour, and after 24 hours of the exercise session.

At the end of the examination, the series of R-R intervals were extracted in text format through the Kubios HRV Standard software for Windows (Kubios Oy, Kuopio, Finland, Release 3.1.0) to obtain the variables related to time and frequency domain measurements of HRV.

The following variables were selected for time domain measurements:

- Root mean square of successive RR interval differences (rMSSD) (ms) (parasympathetic component);

- Percentage of successive RR intervals that differ by more than 50 ms (pNN50) (\%) (parasympathetic component).

- The following variables were selected for frequency domain assessment:

- High frequency (HF) (ms2) (0.15 to $0.4 \mathrm{~Hz}$; parasympathetic component);

- Low frequency (LF)/HF ratio (sympathetic and parasympathetic components with a predominance of the sympathetic component).

The frequency domain measurement of HRV was performed using Fast Fourier Transform (FFT) in intervals of five minutes, with an interpolation of $4 \mathrm{~Hz}$ and $50 \%$ overlap.

\section{Statistical Analysis}

Descriptive statistical analysis was performed using Prism software (GraphPad Inc., San Diego, CA, USA, Release 7.0.0). Normality of data was tested using the Shapiro-Wilk test. Comparisons between the means of the different times of evaluation (baseline, one hour, and 24 hours) were undertaken by repeated measures analysis of variance (ANOVA) along with Dunnett post-hoc test. All measurements were two-tailed, and $P$-values were calculated with significance levels set at $5 \%$. Cohen's effect size (ES) $d$ was calculated to determine the magnitude of the difference between the variables. An ES between 0.20 and 0.49 was considered small, if between 0.50 and 0.79 it was moderate, and an ES $\geq 0.80$ was considered the largest magnitude of effect ${ }^{[16]}$.

\section{RESULTS}

Significant changes in autonomic cardiac control were observed after one AES. Significant differences were found in the time domain, with positive changes in rMSSD (one $[P=0.017]$ and 24 hours [ $P=0.007]$ post-session) (Figure 1 and Table 2). In frequency domain, we found a significant difference in $\mathrm{HF}\left(\mathrm{ms}^{2}\right)$ (one hour $[P=0.048]$ post-session) (Table 2 ). The $L F / H F$ ratio reached statistical significance only after 24 hours $(P=0.018)$ post-session (Figure 1 and Table 2). Additionally, the largest ES was observed only for the LF/HF ratio at one $(d=-0.8)$ and 24 hours ( $d=-1.3)$ post-session.
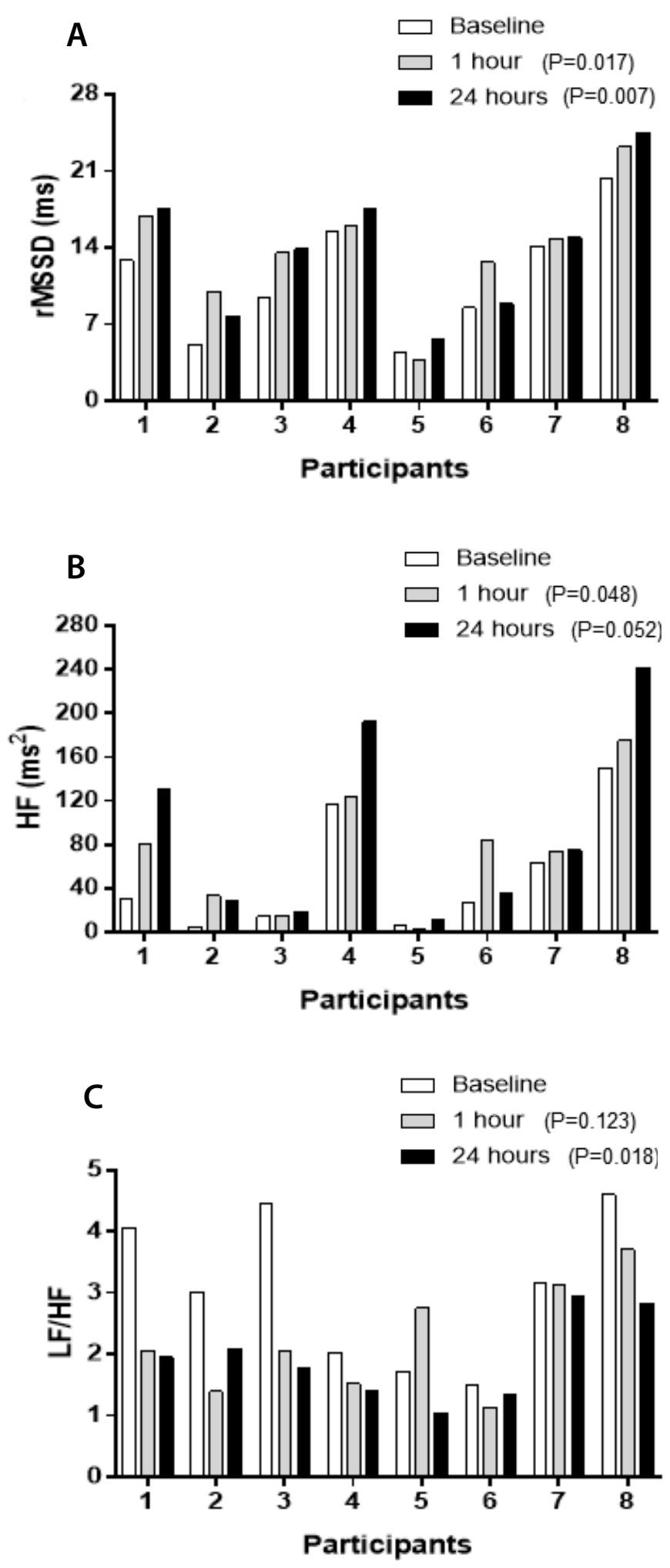

Fig. 1 - Changes in root mean square of successive RR interval differences (rMSSD) (ms), high frequency (HF) (ms'), and low frequency (LF) indexes for each participant before (baseline), after one hour, and after 24 hours of the exercise session. 
Table 2. Comparison between autonomic cardiac control measurements at baseline and at one hour and 24 hours after $A E S$ ( $N=8$ ).

\begin{tabular}{|c|c|c|c|c|c|}
\hline & Baseline & 1 hour & $P$-value & 24 hours & $P$-value \\
\hline & Mean $\pm S D$ & $\Delta$ & & $\Delta$ & \\
\hline \multicolumn{6}{|l|}{ Time domain } \\
\hline rMSSD (ms) & $11.2 \pm 5.4$ & $2.6^{*}$ & 0.017 & $2.6^{+}$ & 0.007 \\
\hline pNN50 (\%) & $0.4 \pm 0.7$ & 0.5 & 0.087 & 0.5 & 0.089 \\
\hline \multicolumn{6}{|c|}{ Frequency domain } \\
\hline $\mathrm{HF}\left(\mathrm{ms}^{2}\right)$ & $51.4 \pm 54.7$ & $21.8^{*}$ & 0.048 & 39.8 & 0.052 \\
\hline LF/HF ratio & $3.1 \pm 1.2$ & -0.9 & 0.123 & $-1.2^{\dagger}$ & 0.018 \\
\hline
\end{tabular}

*Significant differences between baseline and one hour after exercise; ${ }^{\dagger}$ Significant difference between baseline and 24 hours after exercise. AES=aerobic exercise session; HF=high frequency; LF/HF ratio=ratio between low and high frequency components;

pNN50=percentage of successive RR intervals that differ by more than $50 \mathrm{~ms}$; rMSSD=root mean square of successive RR winterval differences; SD=standard deviation

\section{DISCUSSION}

The main finding of the present study lies in the improved autonomic cardiac control in patients undergoing CABG. This was demonstrated by increased vagal modulation (rMSSD [ms] [one hour, $P=0.017$; and 24 hours, $P=0.007$ ], HF [ms 2 ] [one hour, $P=0.048]$ ), and key changes in the LF/HF ratio ( 24 hours, $P=0.007$ ) after one AES.

In a recent review study, Almeida et al. ${ }^{[13]}$ have investigated the benefits promoted by different physical exercise programs after CABG and found only two randomized controlled trials with autonomic variables investigated. These authors pointed to two studies $^{[10,17]}$, demonstrating the benefits of exercise training in the standard deviation of NN intervals (SDNN) index and heart rate $(H R)$ recovery, respectively. Additionally, in a non-randomized controlled trial, Wolszakiewiczet al. ${ }^{[12]}$ have also found improved HRV in patients after CABG.

Given the above, we may say that, in the last 10 years, research associating physical exercise, HRV, and patients after CABG have been underexplored in the relevant literature. In earlier studies (>10 years), some researchers have demonstrated positive effects of exercise in autonomic parameters (heart rate recovery) of patients after $C A B G^{[18,19]}$. However, it is still unclear whether the heart rate recovery has a significant prognostic value for patients after CABG. Thus, further studies about autonomic cardiac control assessed by HRV measurement after exercise training are required.

In this context, the present study evaluated the acute response to aerobic exercise on the autonomic cardiac control of patients undergoing CABG. The largest ES was observed for the LF/HF ratio at one $(d=-0.8)$ and 24 hours $(d=-1.3)$ after AES when compared to baseline. The findings of the present research may have important clinical implications, since higher HRV levels are associated with improved autonomic cardiac control and lower risk of cardiac death. Therefore, the improvements in HRV brought about by the study protocol (aerobic exercise) may reduce the odds of poor outcomes in patients undergoing CABG. In this sense, further randomized controlled trials (chronic intervention) are needed to support our findings.

On the other hand, some studies involving other populations and different intensities, volumes, and types of training would seem to call our findings into question. In this sense, some research studies have highlighted a reduction in HRV, following acute physical exercise ${ }^{[20-23]}$. According to Michael et al. ${ }^{[24]}$, when assessing autonomic cardiac control responses to exercise practice, it is important to analyze how the variables (volume and intensity) are handled and the exercise modality used. Additionally, it seems that the effects of exercise on HRV also depend on how much autonomic cardiac control is committed (i.e., level of the impairment caused by chronic degenerative diseases) $)^{[8,25-28]}$. As such, professionals in the area of cardiac rehabilitation should always bear in mind that acute exercise practice exerts stress on the organism, requiring a balanced prescription between workout and recovery. When the stimulus is adequate in relation to the rest period, we expect recovery and/or that the patients have exercise-related beneficial effects on autonomic cardiac control. In this sense, corroborating our findings, Francica et al. ${ }^{[29]}$ have demonstrated positive effects on HRV in poststroke individuals 20 minutes after the end of exercise test.

In view of the above, the recommendations of the American College of Sports Medicine ${ }^{[15]}$, followed in the present study, may be considered fully adequate for the population of our study, since the physical stress was not severe enough to prevent recovering of the autonomic cardiac control after 35 minutes of the exercise. In addition, improved HRV was demonstrated after aerobic exercise with moderate volume and intensity as mentioned above. In line with our study, Michael et al. ${ }^{[30]}$ have also demonstrated a rapid reactivation of vagal HRV measurements/ values, with a recovery to baseline within 5-10 minutes after exercise practice in the intensity of the first ventilation threshold. According to these authors, exercise above this intensity may result in delayed vagal HRV recovery.

\section{Limitations}

The absence of a control group, the lack of randomization, and the small sample size may be considered limitations. However, given the limited number of published researches involving HRV, exercise, and patients undergoing CABG, our findings may encourage further studies on this topic. 


\section{CONCLUSION}

The practice of (acute) aerobic exercise improved autonomic cardiac control in patients undergoing CABG. However, further randomized controlled trials using the same exercise modality and population of the present study should be undertaken with stricter control of variables (internal and external validity) to lend support to our findings.

\section{ACKNOWLEDGMENTS}

Fabiano de Jesus Furtado Almeida and Vinicius José Nina are grateful to the Fundação de Amparo à Pesquisa e ao Desenvolvimento Científico eTecnológico do Maranhão (FAPEMA).

Financial support: This study was funded by the Fundação de Amparo à Pesquisa e ao Desenvolvimento Científico e Tecnológico do Maranhão (FAPEMA). APP-Universal 01019/13.

\section{No conflict of interest.}

\section{Authors' roles \& responsibilities}

BBG Substantial contributions to the conception or design of the work; or the acquisition, analysis, or interpretation of data for the work; final approval of the version to be published

FJFA Substantial contributions to the conception or design of the work; or the acquisition, analysis, or interpretation of data for the work; final approval of the version to be published

AEAFA Substantial contributions to the conception or design of the work; or the acquisition, analysis, or interpretation of data for the work; final approval of the version to be published

DAFR Substantial contributions to the conception or design of the work; or the acquisition, analysis, or interpretation of data for the work; final approval of the version to be published

RSAG Substantial contributions to the conception or design of the work; or the acquisition, analysis, or interpretation of data for the work; final approval of the version to be published

LFCC Substantial contributions to the conception or design of the work; or the acquisition, analysis, or interpretation of data for the work; final approval of the version to be published

TMSS Substantial contributions to the conception or design of the work; or the acquisition, analysis, or interpretation of data for the work; final approval of the version to be published

VJSN Substantial contributions to the conception or design of the work; or the acquisition, analysis, or interpretation of data for the work; final approval of the version to be published

\section{REFERENCES}

1. Malik M. Clinical guide to cardiac autonomic tests. New York: Springer Science \& Business Media. 1998.

2. Aubert $A E$, Seps $B$, Beckers F. Heart rate variability in athletes. Sports Med. 2003;33(12):889-919. doi:10.2165/00007256-200333120-00003.

3. De Angelis K, Santos MSB, Irigoyen MC. Sistema nervoso autônomo e doença cardiovascular. Rev Soc Cardiol Rio Grande do Sul [Internet]. 2004 [cited 2019 Apr 30];3:1-7. Available from: http://sociedades.cardiol. br/sbc-rs/revista/2004/03/artigo02.pdf.

4. McCraty R, Shaffer F. Heart rate variability: new perspectives on physiological mechanisms, assessment of self-regulatory capacity, and health risk. Glob Adv Health Med. 2015;4(1):46-61. doi:10.7453/ gahmj.2014.073.

5. La Rovere MT, Bigger JT Jr, Marcus Fl, Mortara A, Schwartz PJ. Baroreflex sensitivity and heart-rate variability in prediction of total cardiac mortality after myocardial infarction. ATRAMI (Autonomic Tone and Reflexes After Myocardial Infarction) Investigators. Lancet. 1998;351(9101):478-84. doi:10.1016/S0140-6736(97)11144-8.

6. Kleiger RE, Miller JP, Bigger JT, Moss AJ. Decreased heart rate variability and its association with increased mortality after acute myocardial infarction. Am J Cardiol. 1987;59(4):256-62. doi:10.1016/0002-9149(87)90795-8.

7. Quintana M, Storck N, Lindblad LE, Lindvall K, Ericson M. Heart rate variability as a means of assessing prognosis after acute myocardial infarction: a 3-year follow-up study. Eur Heart J [Internet]. 1997 [cited 2019 Apr 30];18(5):789-97. Available from: https://www.ncbi.nlm.nih. gov/pubmed/9152649.

8. Selig SE, Carey MF, Menzies DG, Patterson J, Geerling RH, Williams AD, et al. Moderate-intensity resistance exercise training in patients with chronic heart failure improves strength, endurance, heart rate variability, and forearm blood flow. J Card Fail. 2004;10(1):21-30. doi:10.1016/S10719164(03)00583-9.

9. Taylor AC, McCartney N, Kamath MV, Wiley RL. Isometric training lowers resting blood pressure and modulates autonomic control. Med Sci Sports Exerc. 2003;35(2):251-6. doi:10.1249/01.MSS.0000048725.15026.B5.

10. Bilińska M, Kosydar-Piechna M, Mikulski T, Piotrowicz E, Gąsiorowska A, PiotrowskiW, et al. Influence of aerobic training on neurohormonal and hemodynamic responses to head-up tilt test and on autonomic nervous activity at rest and after exercise in patients after bypass surgery. Cardiol J. 2013;20(1):17-24. doi:10.5603/CJ.2013.0004.

11. Takeyama J, Itoh H, Kato M, Koike A, Aoki K, Fu LT, et al. Effects of physical training on the recovery of the autonomic nervous activity during exercise after coronary artery bypass grafting. Jpn Circ J [Internet]. 2000 [cited 2019 Apr 30];64(11):809-13. Available from: https://www.ncbi.nlm.nih. gov/pubmed/11110422.

12. Wolszakiewicz J, PiotrowiczE, Foss-Nieradko B, Dobraszkiewicz-Wasilewska B, Piotrowicz R. A novel model of exercise walking training in patients after coronary artery bypass grafting. Kardiol Pol. 2015;73(2):118-26. doi:10.5603/KP.a2014.0165.

13. Almeida FDJF, Gambassi BB, Schwingel PA, Almeida AERAF, Sauaia BA, da Silva Sousa TM, et al. Possible benefits of different physical exercise programs after coronary artery bypass graft surgery: a minireview of selected randomized controlled trials. Sport Sci Health. 2017;13:477. doi:10.1007/s11332-017-0400-7.

14. Borg G. Borg's Perceived Exertion and Pain Scales. Champaign, IL: Human Kinetics. 1998.

15. American College of Sports Medicine (ACSM). ACSM's guidelines for exercise testing and prescription. 9th ed. Philadelphia: LippincottWilliams \&Wilkins. 2013.

16. Cohen, J. Statistical power analysis for the behavioral sciences. 2nd ed. Hillsdale (NJ): Lawrence Erlbaum Associate. 1988.

17. Moholdt TT, Amundsen BH, Rustad LA, Wahba A, Løvø KT, Gullikstad LR, 
et al. Aerobic interval training versus continuous moderate exercise after coronary artery bypass surgery: a randomized study of cardiovascular effects and quality of life. Am Heart J. 2014;158(6):1031-7. doi:10.1016/j. ahj.2009.10.003.

18. Wu SK, Lin YW, Chen CL, Tsai SW. Cardiac rehabilitation vs. home exercise after coronary artery bypass graft surgery: a comparison of heart rate recovery. Am J Phys Med Rehabil. 2006:85(9):711-7. doi:10.1097/01. phm.0000228597.64057.66.

19. Tsai SW, Lin YW, Wu SK. The effect of cardiac rehabilitation on recovery of heart rate over one minute after exercise in patients with coronary artery bypass graft surgery. Clin Rehabil. 2005;19(8):843-9. doi:10.1191/0269215505cr915oa.

20. Rezk CC, Marrache RCB, Tinucci T, Mion D, Forjaz CLDM. Post-resistance exercise hypotension, hemodynamics, and heart rate variability: influence of exercise intensity. Eur J App Physiol. 2006;98(1):105-12. doi:10.1007/ s00421-006-0257-y.

21. Kingsley JD, Figueroa A. Acute and training effects of resistance exercise on heart rate variability. Clin Physiol Funct Imaging. 2016;36(3):179-87. doi:10.1111/cpf.12223.

22. de Paula T, Neves MF, da Silva Itaborahy A, Monteiro W, Farinatti P, Cunha FA. Acute effect of aerobic and strength exercise on heart rate variability and baroreflex sensitivity in men with autonomic dysfunction. J Strength Cond Res. 2017. doi:10.1519/JSC.0000000000002372.

23. Figueiredo T, Menezes $P$, Kattenbraker M, Polito MD, Reis VM, Simão R. Influence of exercise order on blood pressure and heart rate variability after a strength training session. J Sports Med Phys Fitness [Internet].2013 [cited 2019 Apr 30];53(3):12-7. Available from: https://www.researchgate. net/publication/284176625_Influence_of_exercise_order_on_blood_ pressure_and_heart_rate_variability_after_a_strength_training_session. 24. Michael S, Graham KS, Davis GM. Cardiac autonomic responses during exercise and post-exercise recovery using heart rate variability and systolic time intervals - a review. Front Physiol. 2017;8:301. doi:10.3389/ fphys.2017.00301.

25. Gambassi BB, Schwingel PA, Mesquita F, da Penha Carnevali M, de Oliveira D, Sotão SS, et al. Influence of resistance training practice on autonomic cardiac control of hypertensive elderly women. JEPonline [Internet]. 2019 [cited 2019 Apr 30];22(1):37-44. Available from: https://www.asep.org/ asep/asep/JEPonlineFEBRUARY2019_Bruno.pdf.

26. Bhati P, Moiz JA, Menon GR, Hussain ME. Does resistance training modulate cardiac autonomic control? A systematic review and meta-analysis. Clin Auton Res. 2019;29(1):75-103. doi:10.1007/s10286-018-0558-3.

27. Kanegusuku H, Queiroz AC, Silva VJ, Mello MT, Ugrinowitsch C, Forjaz CLM. High-intensity progressive resistance training increases strength with no change in cardiovascular function and autonomic neural regulation in older adults. J Aging Phys Act. 2015;23(3):339-45. doi:10.1123/japa.20120324.

28. Caruso FR, Arena R, Phillips SA, Bonjorno JC Jr, Mendes RG, Arakelian VM. Resistance exercise training improves heart rate variability and muscle performance: A randomized controlled trial in coronary artery disease patients. Eur J Phys Rehabil Med [Internet]. 2015 [cited 2019 Apr 30];51(3):281-9. Available from: https://www.ncbi.nlm.nih.gov/ pubmed/25384514.

29. Francica JV, Bigongiari A, Mochizuki L, Scapini KB, Moraes OA, Mostarda $C$, et al. Cardiac autonomic dysfunction in chronic stroke women is attenuated after submaximal exercise test, as evaluated by linear and nonlinear analysis. BMC Cardiovasc Disord. 2015;15:105. doi:10.1186/ s12872-015-0099-9.

30. Michael S, Jay O, Halaki M, Graham K, Davis GM. Submaximal exercise intensity modulates acute post-exercise heart rate variability. Eur J Appl Physiol. 2016;116(4):697-706. doi:10.1007/s00421-016-3327-9. 